\title{
Predictive value of serum gamma-glutamyltransferase levels in patients with hepatocellular carcinoma
}

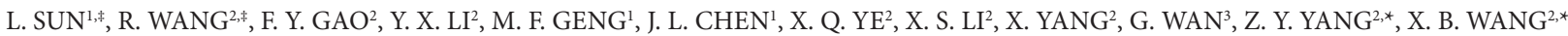 \\ ${ }^{1}$ Dongzhimen Hospital, Beijing University of Chinese Medicine, Beijing 100700, China; ${ }^{2}$ Center of Integrative Medicine, Beijing Ditan Hospital, \\ Capital Medical University, Beijing 100015, China; ${ }^{3}$ Statistics Room, Beijing Ditan Hospital, Capital Medical University, Beijing 100015, China
}

*Correspondence: wangxianbo022714@163.com,yangzhiyun66@163.com

${ }^{*}$ Contributed equally to this work.

Received September 30, 2016 / Accepted November 22, 2016

\begin{abstract}
Here we assessed the predictive value of gamma-glutamyltransferase ( $\gamma$-GT) for the prognosis of patients with HCC and compared the $\gamma$-GT with other prognostic factors. We retrospectively analyzed outcomes for 858 patients first diagnosed with HCC. Cox univariate and multivariate analyses receiver operating characteristic (ROC) curve were used for the study of significance of prognostic factor. A Kaplan-Meier survival analysis was performed to assess the value of $\gamma$-GT as an HCC prognostic factor in different classifications of Barcelona Clinic Liver Cancer (BCLC) or Tumor Node Metastasis (TNM) and different levels of serum alpha fetoprotein (AFP). We showed patient survival rates were significantly associated with $\gamma$-GT as well as serum biological markers including absolute neutrophil count (ANC), absolute lymphocyte count (ALC), AFP. A $\gamma$-GT $\geq 75 \mathrm{U} / \mathrm{L}$ strongly indicated poor prognosis for HCC patients. The survival time of patients with $\gamma$-GT $\geq 75 \mathrm{U} / \mathrm{L}$ was significantly shorter in advanced BCLC and TNM stages and at any serum AFP level. All these results suggested that baseline $\gamma$-GT could effectively aid in determining the prognosis of patients with HCC, and the prognostic value of $\gamma$-GT $\geq 75 \mathrm{U} / \mathrm{L}$ was superior to that of Child-Pugh class, MELD stage, and serum AFP.
\end{abstract}

Key words: $\gamma$-glutamyltransferase, hepatocellular carcinoma, prognosis

In the global rankings of malignant tumor mortality, hepatocellular carcinoma (HCC) is the sixth most deadly and accounts for more than $90 \%$ of primary tumors of the liver $[1,2]$. HCC is a complex multifactor and multistage disease with chronic hepatitis $\mathrm{B}$ or $\mathrm{C}$ infection being the major cause of HCC [3]. Although the extensive application of curative strategies such as resection and liver transplantation, patients at advanced stages or with tumor metastasis or severe liver cirrhosis have to accept palliative treatments, with a five-year survival rate of less than 15\% [4-6]. Therefore, early diagnoses of HCC and prognostic techniques are clinically important. Many HCC grading systems and prognostic scoring models have been proposed, including Child-Pugh class, CLIP (Cancer of the Liver Italian Program) staging, the JIS (Japanese Integrated Staging) scoring system, BCLC (Barcelona-clinic Liver Cancer) staging, TNM (Tumor Node Metastasis) staging, and MELD (Model for End Stage Liver diseases) [7-9]. However, these systems are very complicated, and international scholars have not reached a consensus concerning which classification system is best for diagnosis and prognostic evaluation in HCC patients. Therefore, some simpler and more effective serum biomarkers to guide clinical prevention and treatment of HCC are required to find. Alpha fetoprotein (AFP) has been reported to be an important serological marker in HCC diagnosis and monitoring, however, about $40 \%$ of early-phase patients and $15 \%-30 \%$ of late-phase patients can still be negative for AFP $[10,11]$.

$\gamma$-glutamyltransferase $(\gamma-G T)$ is a key enzyme in the processing of glutathione and related molecules. $\gamma$-GT plays a role in transpeptidation and hydrolysis and is involved in bioconversion, metabolism of nucleic acids, and neoplasia $[12,13]$. Recently, serum $\gamma$-GT level has also been characterized as a biomarker for oxidative stress and has been shown to correlate with inflammation in the extracellular tissue microenvironment $[14,15]$. Over the last few years, several studies have focused on the possible relationship between $\gamma$-GT and HCC incidence, development, recurrence, 
and poor prognosis. Elevated $\gamma$-GT has been suggested as a promising predictor of poor survival rates in HCC patients after hepatectomy, transcatheter arterial chemoembolization (TACE), or radiofrequency ablation (RFA). However, these investigations focused on studying a single treatment [15]. Given that HCC can present with obvious tumor heterogeneity, quick progression, intrahepatic and distant metastasis, low resection rate, high postoperative recurrence rate, hepatic dysfunction, and hepatitis virus replication, integrated treatment modalities are more clinically common than single treatments [5].

To address these problems, we firstly analyzed whether, in integrated treatment modalities, serum levels of $\gamma$-GT could aid in the prognosis for patients with HCC. We also compared the prognostic value of $\gamma$-GT with other prognostic indices and models. The predictive value of different $\gamma$-GT levels for patients at different stages of HCC was also analyzed. Finally, we juxtaposed observations of both $\gamma$-GT and AFP levels and discussed whether $\gamma$-GT can improve the accuracy of predictions using AFP.

\section{Patients and methods}

Patients. Between January 2008 and March 2013, 1005 patients in Beijing Ditan Hospital, Capital Medical University, were first diagnosed with HCC. We excluded 147 patients who were less than 18 years old or who had incomplete or missing medical records regarding tumor number, tumor size, clinical symptoms, laboratory results, and imaging results, with a remaining population of 858 patients. Patients with one of the following criteria were diagnosed with HCC: (1) the presence of cells or histological evidence of HCC; (2) pathological changes that could be recognized in at least two different imaging examinations; (3) an imageological examination that showed the pathological changes of HCC combined with a serum AFP $\geq 400 \mathrm{ng} / \mathrm{mL}$ [16]. The most commonly used diagnostic imaging tools were hepatic angiography, magnetic resonance imaging (MRI), abdominal computed tomography (CT), and transabdominal ultrasonography.

Patients in our study who met the criteria of the American Association for the Study of Liver Diseases (AASLD) for liver resection and liver transplantation received appropriate surgical treatment. Patients who were not suitable candidates for surgery were given local treatment, including transarterial embolization and ablation [16]. Patients who could not accept either of the above-mentioned treatments were placed on regimens of either sorafenib or the three-drug combination of folinic acid, fluorouracil, and oxaliplatin. Patients with a Child-Pugh class of $\mathrm{C}$ or with distant metastases received the best supportive care (BSC) and corresponding treatments recommended by international guidelines. In addition, all patients were assessed based on their specific underlying circumstances (e.g., chronic hepatitis, cirrhosis, liver dysfunction, or other concomitant diseases) and received appropriate treatment to protect the liver, reduce enzymes, and treat the respective viruses or other conditions [17].

The study protocol was developed in accordance with the Declaration of Helsinki's code of ethics and was approved by the Beijing Ditan Hospital ethics committee (Beijing, China) [18]. Because the study was of a retrospective design, informed consent of all patients could not be obtained. However, patient records and information were anonymized prior to analysis to protect patient privacy.

Study variables. All study variables were baseline data at the time of diagnosis. The patient demographic and medical history characteristics analyzed included gender, age, survival time, family history of HCC, history of smoking, history of alcohol use, basic disease complications (including seroperitoneum, esophageal and gastric varices, hepatic encephalopathy, spontaneous bacterial peritonitis, hepatorenal syndrome, hypersplenism, and upper gastrointestinal hemorrhage), comorbidity (including diabetes, hypertension, coronary heart disease, valvular heart disease, kidney failure, and abnormal thyroid function), and courses of treatment. Patient serum biochemical and clinical characteristics included $\gamma$-GT, AFP, prothrombin activity (PTA), prothrombin time (PT), absolute lymphocyte count (ALC), absolute neutrophil count (ANC), white blood cell (WBC) count, absolute platelet count (PLT), serum albumin (ALB), alanine aminotransferase (ALT), aspartate aminotransferase (AST), alkaline phosphatase (ALP), total bilirubin (TBil), serum creatinine (Cr), international normalized PT ratio, MELD staging, and Child-Pugh class. Tumor-associated indexes including the number and size of tumor, lymph node involvement, portal vein invasion, and distant metastasis were based on CT or MRI examination results. Staging using the BCLC and TNM systems adopted the latest standards as of 2010. For the purposes of this study, patient survival was assessed at the end of a 5-year follow-up period after diagnosis.

Statistical analysis. All data in this study were analyzed by SPSS 19.0 software (IBM, Armonk, NY) [19, 20]. Categorical data were described by frequency and percentage. Continuous variables that obey normal distribution were reported with mean \pm standard deviation, and variables with non-normal distribution were reported with median (Q1-Q3). The Cox proportional hazards model was adopted for univariate and multivariate analyses [21]. Cox multivariate analyses were completed using a forward stepwise method based on likelihood ratios. The prediction accuracy of the observation indexes in this study for the survival rates of patients were evaluated using a receiver operating characteristic (ROC), and the area under ROC curve (AUC) was compared to assess the discriminatory capacity of each index [22]. In this way, we calculated the AUC, sensitivity and specificity and found the cut-off value for the maximum sensitivity and specificity of $\gamma$-GT. Survival analyses were conducted using the KaplanMeier method, and a log-rank test was performed to calculate the differences between groups. For all comparisons, a $P$-value $<0.05$ was considered statistically significant. 
Table 1. The characteristics of HCC patients $(n=858)$

\begin{tabular}{|c|c|}
\hline Variables & $\dagger$ †alue \\
\hline Age (years) & $55.0(48.0-61.0)$ \\
\hline Gender (male/female) & $712 / 146$ \\
\hline Family history of HCC & 111 \\
\hline History of alcohol use & 337 \\
\hline History of smoking & 336 \\
\hline \multicolumn{2}{|l|}{ Pathogenesis basis } \\
\hline HBV & 666 \\
\hline $\mathrm{HCV}$ & 52 \\
\hline Alcoholic liver disease & 21 \\
\hline $\mathrm{HBV}+$ Alcoholic liver disease & 88 \\
\hline $\mathrm{HCV}+$ Alcoholic liver disease & 11 \\
\hline $\mathrm{HBV}+\mathrm{HCV}$ & 4 \\
\hline $\mathrm{HBV}+\mathrm{HCB}+$ Alcoholic liver disease & 3 \\
\hline Unknown aetiology & 13 \\
\hline \multicolumn{2}{|l|}{ Complications } \\
\hline Seroperitoneum & 340 \\
\hline Esophageal and fundal varices & 608 \\
\hline Hepatic encephalopathy & 26 \\
\hline SBP & 13 \\
\hline Hepatorenal syndrome & 13 \\
\hline Hypersplenism & 124 \\
\hline Upper gastrointestinal bleeding & 44 \\
\hline \multicolumn{2}{|l|}{ Tumor-related factors } \\
\hline Number of tumors $\geq 3$ (yes/no) & $309 / 549$ \\
\hline Tumor size $\geq 5 \mathrm{~cm}$ (yes/no) & $286 / 572$ \\
\hline Portal vein invasion (yes/no) & $221 / 637$ \\
\hline Lymph node metastasis (yes/no) & $75 / 801$ \\
\hline \multicolumn{2}{|l|}{ Underlying liver status factors } \\
\hline ALT (IU/L) & $37.1(24.8-60.5)$ \\
\hline AST (IU/L) & $45.6(30.0-74.6)$ \\
\hline $\operatorname{TBil}(\mu \mathrm{mol} / \mathrm{L})$ & $20.2(13.7-30.9)$ \\
\hline $\operatorname{ALB}(\mathrm{g} / \mathrm{L})$ & $37.0(31.8-41.1)$ \\
\hline $\operatorname{ALP}(\mathrm{U} / \mathrm{L})$ & $100.9(77.0-414.3)$ \\
\hline$\gamma-\mathrm{GT}(\mathrm{U} / \mathrm{L})$ & $64.6(31.9-138.8)$ \\
\hline $\mathrm{WBC}(\times 109 / \mathrm{L})$ & $4.5(3.2-5.8)$ \\
\hline $\mathrm{ANC}\left(\times 10^{9} / \mathrm{L}\right)$ & $2.6(1.7-3.7)$ \\
\hline $\operatorname{ALC}\left(\times 10^{9} / \mathrm{L}\right)$ & $1.1(0.8-1.6)$ \\
\hline $\operatorname{PLT}\left(\times 10^{9} / \mathrm{L}\right)$ & $97.0(61.1-148.7)$ \\
\hline $\mathrm{Cr}(\mu \mathrm{mol} / \mathrm{L})$ & $66.0(57.3-77.0)$ \\
\hline PTA (\%) & $74.2(63.4-87.1)$ \\
\hline HBV-DNA level $\left(\log _{10}\right.$ copies $\left.\bullet \mathrm{mL}^{-1}\right)$ & $3.9 \pm 1.4$ \\
\hline MELD & $5.2(2.7-8.2)$ \\
\hline $\mathrm{AFP} \geq 400 \mathrm{ng} / \mathrm{mL}$ & 235 \\
\hline \multicolumn{2}{|l|}{ Child-Pugh class } \\
\hline A & 538 \\
\hline B & 260 \\
\hline $\mathrm{C}$ & 60 \\
\hline
\end{tabular}

$\mathrm{HCC}=$ hepatocellular carcinoma, $\mathrm{HBV}=$ hepatitis $\mathrm{B}$ virus, $\mathrm{HCV}=$ hepatitis $\mathrm{C}$ virus, $\mathrm{ALT}=$ alanine aminotransferase, $\mathrm{AST}=$ aspartate aminotransferase, TBil $=$ total bilirubin, $\mathrm{ALB}=$ serum albumin, $\mathrm{ALP}=$ alkaline phosphatase, $\gamma$-GT $=\gamma$-glutamyltransferase, $\mathrm{WBC}=$ white blood cell, $\mathrm{ANC}=$ absolute neutrophil count, ALC = absolute lymphocyte count, PLT = platelet count, $\mathrm{Cr}=$ serum creatinine, $\mathrm{PTA}=$ prothrombin activity, $\mathrm{AFP}=\alpha$-fetoprotein, MELD $=$ Model for End-Stage Liver Disease.

$\dagger$ Data are presented as the number of observations or the median or the mean \pm standard deviation.

${ }^{\star} P<0.05$

\section{Results}

Patient characteristics and outcomes. The baseline characteristics of 858 patients with HCC were shown in Table 1. The median age was $55.0(48.0-61.0)$. These patients included $712(83.0 \%)$ male and $146(17.0 \%)$ female. In addition, 111 $(12.9 \%)$ had a family history of HCC. HBV and HCV infection, and alcoholic liver disease were diagnosed in 666 (77.6\%), $52(6.1 \%)$, and $21(2.4 \%)$ patients, respectively. Of the 666 patients with HBV, the level of HBV-DNA was $3.9 \pm 1.4 \log _{10}$ copies $\bullet \mathrm{mL}^{-1}$ in 572 of them, all of whom received antiretroviral therapy. Coinfection of HBV and HCV was diagnosed in $4(0.5 \%)$ patients, $\mathrm{HBV}$ and alcoholic liver disease in 88 (10.3\%) patients, and HCV with alcoholic liver disease in 11 (1.3\%) patients. Coinfection with HBV, HCV, and alcoholic liver disease was found in $3(0.3 \%)$ patients. The causes of HCC were unknown in 13 (1.5\%) patients. At diagnosis, 340 patients had seroperitoneum, 608 hadesophageal and gastric varices, 26 had hepatic encephalopathy, 13 had spontaneous bacterial peritonitis, 13 had hepatorenal syndrome, 124 had hypersplenism, and 44 had upper gastrointestinal hemorrhage. Comorbidity was present in 310 patients, including 166 with diabetes, 205 with hypertension, 9 with coronary heart disease, 1 with valvular heart disease, 2 with kidney failure, 3 with abnormal thyroid function, and 3 with other inflammatory disease (serious infection/sepsis).

A Child-Pugh classification of A, B, and C was found in $538(62.7 \%), 260(30.3 \%)$, and $60(7.0 \%)$ patients, respectively. A tumor $\geq 5 \mathrm{~cm}$ was found in $286(33.3 \%)$ patients, and tumor number $\geq 3$ was found in 309 (36.0\%). Among all 858 patients, $75(8.7 \%)$ and 221 (25.8\%) were diagnosed with lymph node metastasis and portal vein involvement, respectively.

Ninety-one $(10.6 \%)$ patients were treated with surgical resection, and $661(77.0 \%)$ patients accepted locoregional treatment. Hepatectomy was combined with TACE in 28 patients, combined with RFA in three patients, and with both TACE and RFA in 17 patients. The remaining 154 (17.9\%) patients received BSC. During the follow-up period, the 6-, 12-, 18 -, and 24 -month survival rates were $76.7 \%, 63.6 \%, 55.7 \%$, and $50.6 \%$, respectively. At the end of the 2 -year follow-up period, 424 (49.4\%) patients had died.

Prognostic value of baseline $\gamma$-GT in HCC. The 39 characteristics observed in this study (Table 2) were analyzed using univariate analysis. We found that the following characteristics were related to the survival rates of patients with HCC $(P<$ $0.05)$ : gender, age, history of alcohol use, tumor diameter $\geq$ $5 \mathrm{~cm}$, tumor number $\geq 3$, portal vein invasion, lymph node involvement, $\mathrm{HCV}$ infection, alcoholic liver disease, HBV/ alcoholic liver disease coinfection, seroperitoneum, esophageal and gastric varices, hepatic encephalopathy, spontaneous bacterial peritonitis (SBP), hepatorenal syndrome, upper gastrointestinal hemorrhage, $\gamma$-GT, AST, ALB, TBil, Cr, ALP, PTA, ANC, PLT, ALC, WBC, AFP $\geq 400$ ng/mL, Child-Pugh class, and MELD score. The above-mentioned factors selected from the univariate analysis received a further multivariate 
Table 2. Univariate and multivariate of factors associated with early death

\begin{tabular}{|c|c|c|}
\hline Variable & $\begin{array}{c}\text { Univariate } \\
\text { HR }(95 \% \text { CI })\end{array}$ & $\begin{array}{l}\text { Multivariate } \\
\text { HR }(95 \% \text { CI }) \\
\end{array}$ \\
\hline Age (years) & $0.984(0.975-0.994)^{*}$ & \\
\hline Gender (male/female) & $0.641(0.483-0.851)^{*}$ & \\
\hline Family history of HCC & $1.187(0.903-1.559)$ & \\
\hline History of alcohol use & $1.591(1.314-1.925)^{*}$ & \\
\hline History of smoking & $1.238(1.022-1.501)^{\star}$ & \\
\hline \multicolumn{3}{|l|}{ Pathogenesis basis } \\
\hline HBV & $0.834(0.669-1.041)$ & \\
\hline $\mathrm{HCV}$ & $0.586(0.366-0.940)^{*}$ & \\
\hline Alcoholic liver disease & $1.706(1.019-2.856)^{*}$ & \\
\hline HBV+Alcoholic liver disease & $1.627(1.228-2.156)^{*}$ & \\
\hline HCV+Alcoholic liver disease & $1.487(0.705-3.139)$ & \\
\hline $\mathrm{HBV}+\mathrm{HCV}$ & $0.049(0.000-10.643)$ & \\
\hline $\begin{array}{l}\mathrm{HBV}+\mathrm{HCB}+\text { Alcoholic } \\
\text { liver disease }\end{array}$ & $0.742(0.104-5.280)$ & \\
\hline Unknown aetiology & $1.048(0.496-2.212)$ & \\
\hline \multicolumn{3}{|l|}{ Complications } \\
\hline Seroperitoneum & $2.408(1.988-2.917)^{*}$ & \\
\hline Esophageal and fundal varices & $1.747(1.388-2.199)^{*}$ & \\
\hline Hepatic encephalopathy & $1.638(1.008-2.661)^{*}$ & \\
\hline SBP & $2.791(1.489-5.230)^{*}$ & \\
\hline Hepatorenal syndrome & $3.677(2.018-6.701)^{*}$ & \\
\hline Hypersplenism & $0.881(0.668-1.162)$ & \\
\hline Upper gastrointestinal bleeding & $1.772(1.207-2.603)^{\star}$ & \\
\hline \multicolumn{3}{|l|}{ Tumor-related factors } \\
\hline Number of tumors $\geq 3$ (yes/no) & $2.716(2.242-3.290)^{*}$ & $1.459(1.176-1.809)^{*}$ \\
\hline Tumor size $\geq 5 \mathrm{~cm}$ (yes/no) & $3.828(3.152-4.649)^{*}$ & $1.635(1.297-2.060)^{*}$ \\
\hline Portal vein invasion (yes/no) & $9.148(7.426-11.269)^{*}$ & $4.100(3.137-5.359)^{*}$ \\
\hline Lymph node metastasis (yes/no) & $3.920(3.026-5.077)^{\star}$ & $1.703(1.289-2.251)^{*}$ \\
\hline \multicolumn{3}{|l|}{ Underlying liver status factors } \\
\hline ALT (IU/L) & $1.001(1.000-1.002)$ & \\
\hline AST (IU/L) & $1.003(1.002-1.004)^{*}$ & \\
\hline $\operatorname{TBil}(\mu \mathrm{mol} / \mathrm{L})$ & $1.007(1.006-1.009)^{*}$ & \\
\hline $\operatorname{ALB}(g / L)$ & $0.962(0.949-0.976)^{*}$ & \\
\hline $\operatorname{ALP}(\mathrm{U} / \mathrm{L})$ & $1.005(1.004-1.006)^{\star}$ & \\
\hline$\gamma$-GT (U/L) & $1.004(1.003-1.004)^{*}$ & $1.001(1.000-1.002)^{*}$ \\
\hline WBC $(\times 109 / L)$ & $1.188(1.133-1.246)^{*}$ & \\
\hline ANC $\left(\times 10^{9} / \mathrm{L}\right)$ & $1.394(1.319-1.472)^{*}$ & $1.298(1.217-1.384)^{*}$ \\
\hline $\operatorname{ALC}\left(\times 10^{9} / \mathrm{L}\right)$ & $0.535(0.448-0.639)^{\star}$ & $0.554(0.442-0.694)^{*}$ \\
\hline $\operatorname{PLT}\left(\times 10^{9} / \mathrm{L}\right)$ & $1.003(1.001-1.004)^{\star}$ & \\
\hline $\mathrm{Cr}(\mu \mathrm{mol} / \mathrm{L})$ & $1.005(1.003-1.007)^{\star}$ & \\
\hline PTA (\%) & $0.982(0.977-0.987)^{\star}$ & \\
\hline MELD & $1.053(1.039-1.068)^{*}$ & \\
\hline $\mathrm{AFP} \geq 400 \mathrm{ng} / \mathrm{mL}$ & $3.255(2.679-3.955)^{*}$ & $1.486(1.187-1.861)^{*}$ \\
\hline \multicolumn{3}{|l|}{ Child-Pugh class } \\
\hline \multicolumn{3}{|l|}{ A } \\
\hline B & $2.125(1.731-2.608)^{\star}$ & $1.596(1.271-2.004)^{*}$ \\
\hline $\mathrm{C}$ & $4.843(3.558-6.592)^{*}$ & $4.655(3.323-6.522)^{*}$ \\
\hline
\end{tabular}

$\mathrm{HR}=$ hazard ratio, $\mathrm{CI}=$ confidence interval, $\mathrm{HCC}=$ hepatocellular carcinoma, $\mathrm{HBV}=$ hepatitis $\mathrm{B}$ virus, $\mathrm{HCV}=$ hepatitis $\mathrm{C}$ virus, $\mathrm{ALT}=$ alanine aminotransferase, $\mathrm{AST}=$ aspartate aminotransferase, $\mathrm{TBil}=$ total bilirubin, $\mathrm{ALB}=$ serum albumin, $\mathrm{ALP}=$ alkaline phosphatase, $\gamma$-GT $=\gamma$-glutamyltransferase, $\mathrm{WBC}=$ white blood cell, ANC $=$ absolute neutrophil count, $\mathrm{ALC}=$ absolute lymphocyte count, $\mathrm{PLT}=$ platelet count, $\mathrm{Cr}=$ serum creatinine, $\mathrm{PTA}=$ prothrombin activity, $\mathrm{AFP}=\alpha$-fetoprotein, $\mathrm{MELD}=$ Model for End-Stage Liver Disease. ${ }^{\star} P<0.05$

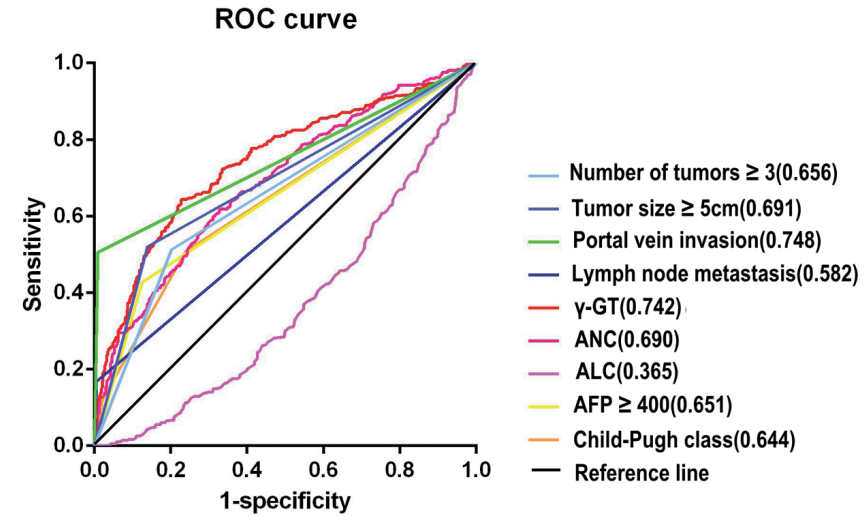

Figure 1. ROC curve of risk factors related to survival rates of HCC patients, revealed in multivariate analysis. $\mathrm{ROC}=$ receiver operating characteristic, $\mathrm{AUC}=$ area under the curve, $\gamma$-GT $=\gamma$-glutamyltransferase, $\mathrm{ALC}=$ absolute lymphocyte count, $\mathrm{ANC}=$ absolute neutrophil count, $\mathrm{Cr}=$ serum albumin, AFP $=\boldsymbol{\alpha}$-fetoprotein, HCC $=$ hepatocellular carcinoma.

Cox regression analysis, revealing that the following were significantly related to the survival rates of patients $(P<0.05$, Table 2): $\gamma$-GT, ANC, ALC, AFP $\geq 400 \mathrm{ng} / \mathrm{mL}$, tumor diameter $\geq 5 \mathrm{~cm}$, tumor number $\geq 3$, lymph node involvement, portal vein invasion, and Child-Pugh class.

Drawing the ROC curve of the selected indictors from the multivariate analysis, we compared their predictive values in making an HCC prognosis. The ROC curve for $\gamma$-GT (0.742) had the largest AUC among the serum biochemical markers, compared with that of portal vein invasion (0.748), tumor diameter $\geq 5 \mathrm{~cm}(0.691)$, ANC (0.690), tumor number $\geq 3$ (0.656), AFP $\geq 400 \mathrm{ng} / \mathrm{mL}$ (0.651), Child-Pugh class (0.644), lymph node involvement (0.582) and ALC (0.365) (Figure 1). The above analysis revealed that baseline $\gamma$-GT levels in HCC prognosis had important predictive values. We set $75 \mathrm{U} / \mathrm{L}$ as the $\gamma$-GT cut-off value at which level the sensitivity was $64.9 \%$ and the specificity was $77.0 \%$. In the Kaplan-Meier analysis shown in Figure 2, the 6-, 12-, 18- and 24-month survival

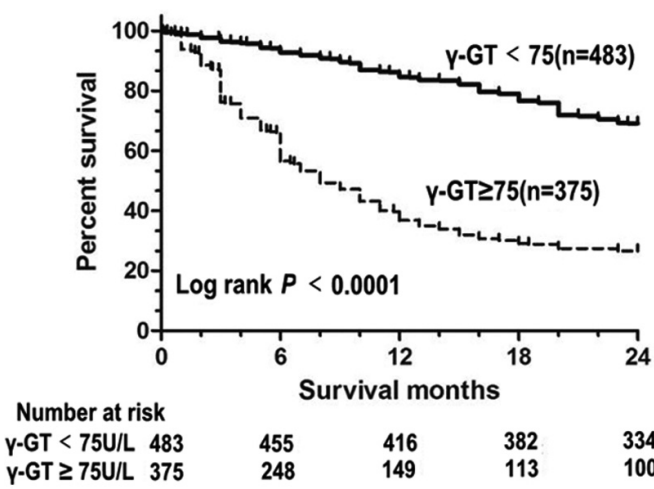

Figure 2. Kaplan-Meier survival curves of HCC patients with a $\gamma$-GT level $\geq 75 \mathrm{U} / \mathrm{L}$ and those with a $\gamma$-GT level $<75 \mathrm{U} / \mathrm{L}$ over the 2 -year follow up period. 

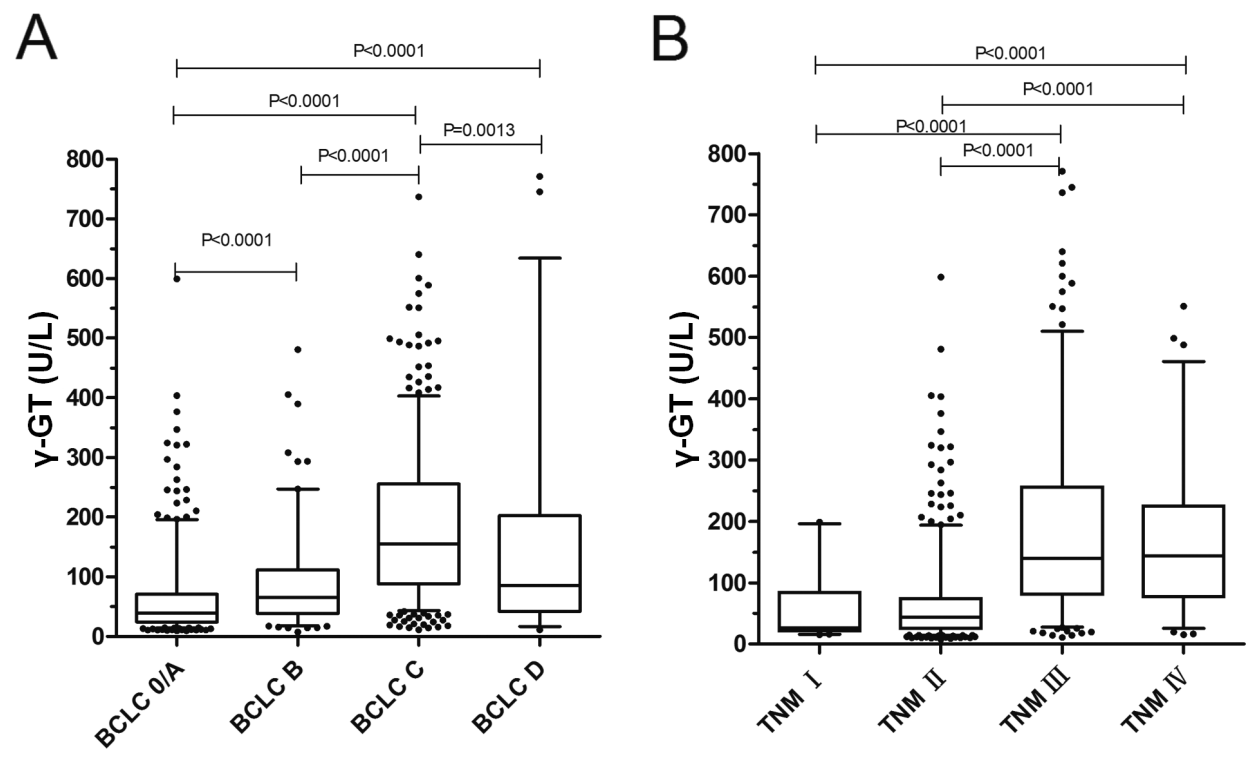

Figure 3. Box plots showing $\gamma$-GT levels in HCC patients with different BCLC and TNM stages. $\gamma$-GT $=\gamma$-glutamyltransferase, HCC $=$ hepatocellular carcinoma, BCLC = Barcelona-Clinic Liver Cancer, TNM = Tumor Node Metastasis.

rates of patients with serum $\gamma$-GT level $\geq 75 \mathrm{U} / \mathrm{L}(56.5 \%$, $36.8 \%, 29.1 \%, 26.7 \%$, respectively) were significantly lower $(P<0.0001)$ than those with $\gamma$-GT $<75 \mathrm{U} / \mathrm{L}(92.8 \%, 84.7 \%$, $76.6 \%$ and $69.2 \%$, respectively).

Baseline $\gamma$-GT's relationship with the BCLC and TNM staging systems of HCC. In this study, we evaluated the relationship between baseline $\gamma$-GT level and BCLC or TNM stages. In BCLC stages 0/A-C, the baseline $\gamma$-GT levels were gradually increased with development of BCLC grades (Figure $3 \mathrm{~A}, P<0.0001)$, with $\gamma$-GT levels at stage $0 / \mathrm{A}$ of $38.90 \mathrm{U} / \mathrm{L}$ (23.98-70.43 U/L), at stage B of $62.50 \mathrm{U} / \mathrm{L}(38.00-111.90 \mathrm{U} / \mathrm{L})$, and at stage $\mathrm{C}$ of $155.05 \mathrm{U} / \mathrm{L}(87.80-255.55 \mathrm{U} / \mathrm{L})$. However, the $\gamma$-GT levels $85.20 \mathrm{U} / \mathrm{L}(41.65-202.2 \mathrm{U} / \mathrm{L})$ at stage $\mathrm{D}$ were decreased compared with stage $C(P=0.0013)$. In addition, we showed that differences in levels of $\gamma$-GT between phase I and II were not significant $(P=0.2093)$, but the level of $\gamma$-GT in phase III increased significantly compared with phase I and phase II $(P<0.0001)$. The phenomenon of $\gamma$-GT levels decreasing in BCLC stage D compared with the pervious stage was not observed when comparing TNM stage III to stage IV $(P=0.4204)$.

Moreover, we also performed a Kaplan-Meier survival analysis of the $\gamma$-GT cut-off value in different stages of BCLC or TNM in HCC prognosis (Figure 4). In BCLC stages B $(P=$ $0.0075), \mathrm{C}(P<0.0001)$, and $\mathrm{D}(P=0.0090)$, the survival rates of patients with a $\gamma$-GT level $\geq 75 \mathrm{U} / \mathrm{L}$ were significantly lower than that of patients with a $\gamma$-GT level $<75 \mathrm{U} / \mathrm{L}$ throughout the follow-up period (Figure 4B-D), but not significantly in BCLC stage $0 / \mathrm{A}(P=0.1189)$. In the TNM stages II, III, and IV ( $P=0.0025, P<0.0001, P=0.0164$, respectively $)$, the survival rates of patients with a $\gamma$-GT level $\geq 75 \mathrm{U} / \mathrm{L}$ was significantly poorer than for those with $\gamma-\mathrm{GT}<75 \mathrm{U} / \mathrm{L}$ throughout the follow-up period, however not significantly for patients classified as TNM stage I $(P=0.6171)$ (Figure 4F-H).

Correlation of baseline $\gamma$-GT cut-off value with serum AFP levels in HCC. Using Kaplan-Meier survival analysis, we examined the prognostic value for HCC of using the $\gamma$-GT cut-off value for the following three serum AFP levels: AFP $<8.8 \mathrm{ng} / \mathrm{mL}, 8.8 \mathrm{ng} / \mathrm{mL} \leq \mathrm{AFP}<400 \mathrm{ng} / \mathrm{mL}$, and AFP $\geq 400 \mathrm{ng} / \mathrm{mL}$ (where the normal reference value is $0.9-8.8$ $\mathrm{ng} / \mathrm{mL}$ ). The results showed that the survival rate of patients with a $\gamma$-GT level $\geq 75 \mathrm{U} / \mathrm{L}$ was significantly lower at all 3 AFP levels compared to that of patients with a $\gamma$-GT level $<$ $75 \mathrm{U} / \mathrm{L}(P<0.0001)$ (Figure 5). Thus, irrespective of serum AFP levels, the $\gamma$-GT cut-off value has important predictive value for the prognosis of HCC patients, with important clinical significance for serum AFP-negative HCC patients in predicting their outcomes.

Correlation of baseline $\gamma$-GT cut-off value with alcohol consumption. We examined the predictive value of a baseline $\gamma$-GT cut-off value in the prognosis of HCC in patients with alcohol cause and without alcohol cause by using KaplanMeier survival analysis. The results showed that the survival rates of patients with a $\gamma$-GT level $\geq 75 \mathrm{U} / \mathrm{L}$ was significantly lower, compared to that of patients with a $\gamma$-GT level $<75 \mathrm{U} / \mathrm{L}$ $(P<0.0001)$ (Figure 6) regardless of alcohol cause, suggesting that alcohol consumption did not affect the predictive value of $\gamma$-GT in the prognosis of patients with HCC.

\section{Discussion}

In the past 10 years, various studies have revealed that serum $\gamma$-GT is a predictive clinical outcome marker in a variety of malignant tumors, including HCC [13, 23-25]. Previous 
A

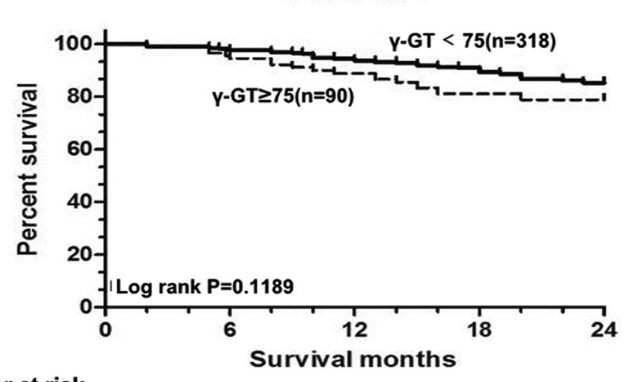

Number at risk $\begin{array}{lccccc}\text { Y }- \text { GT }<75 \mathrm{U} / \mathrm{L} & 318 & 312 & 300 & 289 & 271 \\ \mathrm{Y}-\mathrm{GT} \geq 75 \mathrm{~L} / \mathrm{L} & 90 & 86 & 81 & 75 & 71\end{array}$

C

BCLC C

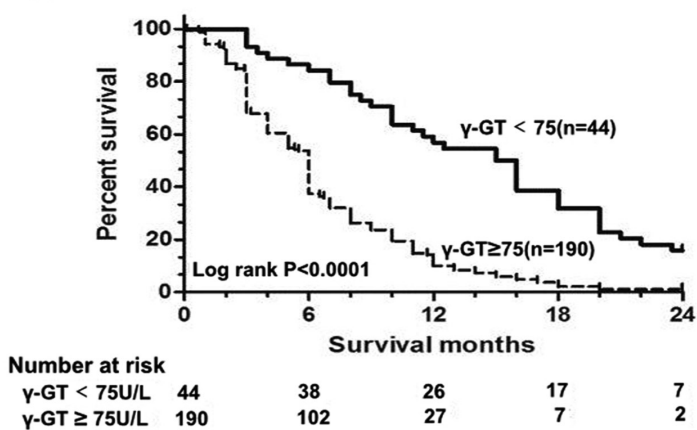

$E$

TNM I

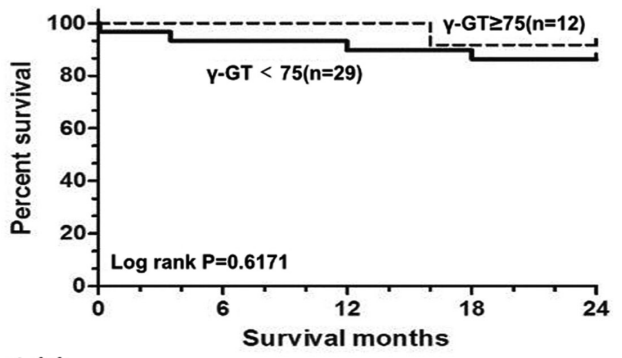

Number at risk Y-GT $<75 U / L \quad 29$ $Y-G T \geq 75 U / L \quad 12$

G

TNM III

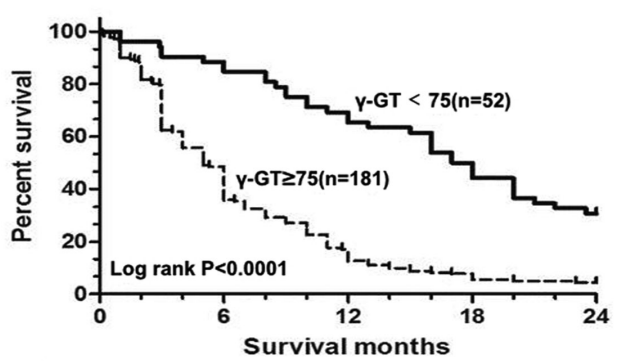

Number at risk

$\begin{array}{lllllr}\mathrm{Y}-\mathrm{GT}<75 \mathrm{U} / \mathrm{L} & 52 & 46 & 36 & 26 & 16 \\ \mathrm{Y}-\mathrm{GT} \geq 75 \mathrm{~L} & 181 & 88 & 31 & 14 & 8\end{array}$
B

BCLC B

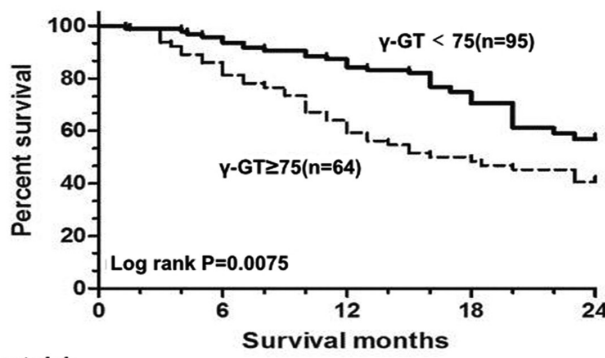

Number at risk

$\begin{array}{llllll}\mathrm{Y}-\mathrm{GT}<75 \mathrm{C} / \mathrm{L} & 95 & 91 & 83 & 71 & 54\end{array}$
$D$

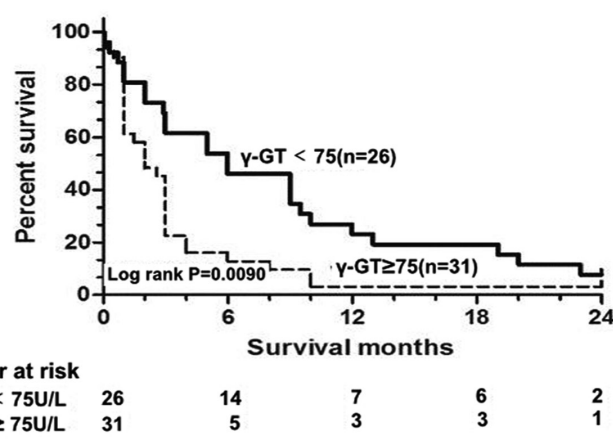

F

TNM II

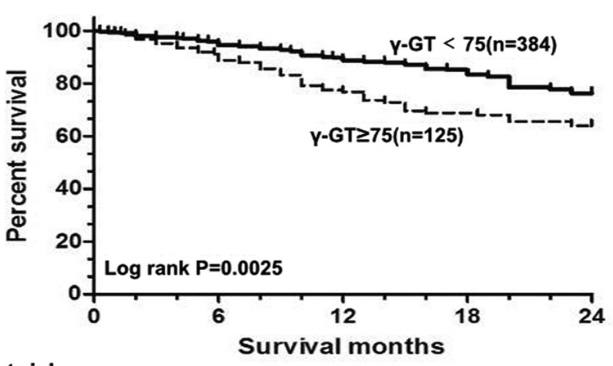

Number at risk

Y-GT < 75U/L

V-GT $\geq 75 \mathrm{~V} / \mathrm{L} \quad 125$

$H$

TNM IV

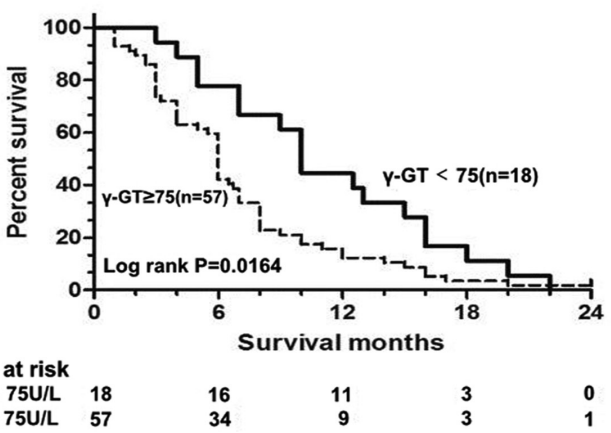

Figure 4. Kaplan-Meier survival curves of HCC patients with $\gamma$-GT $\geq 75 \mathrm{U} / \mathrm{L}$ and $<75 \mathrm{U} / \mathrm{L}$ in different stages of BCLC and TNM. $\gamma$-GT $=$ $\gamma$-glutamyltransferase, HCC $=$ hepatocellular carcinoma, BCLC = Barcelona-Clinic Liver Cancer, TNM = Tumor Node Metastasis . 

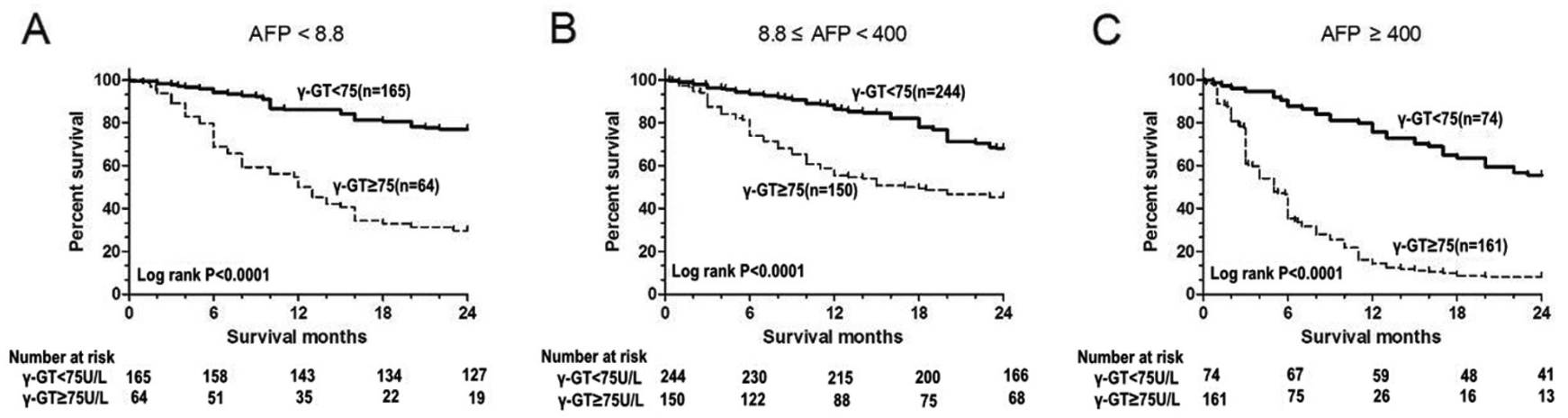

Figure 5. Kaplan-Meier survival curves at different levels of serum AFP comparing HCC patients with a $\gamma$-GT level $\geq 75$ U/L to those with a $\gamma$-GT level $<75 \mathrm{U} / \mathrm{L}$.
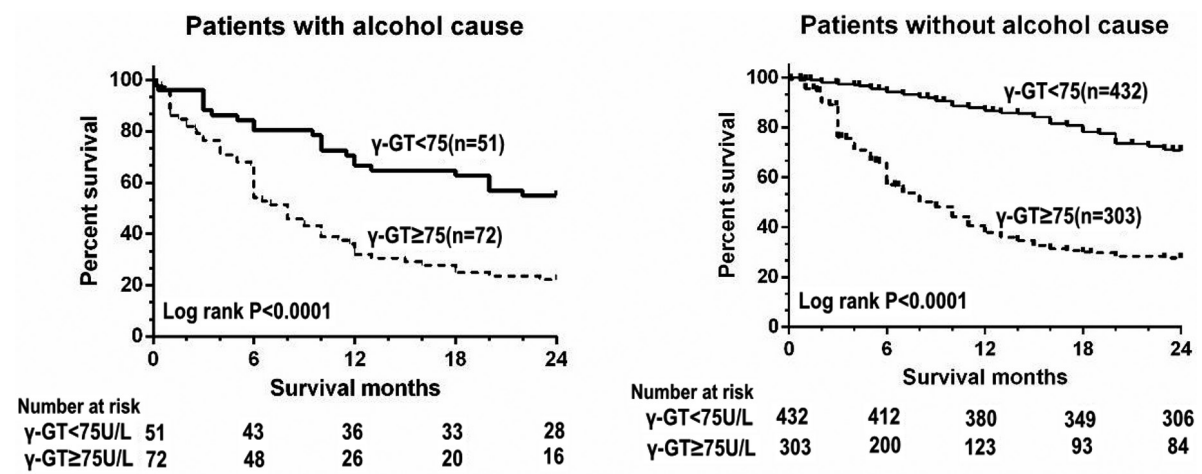

Figure 6. Kaplan-Meier survival curves of HCC patients with $\gamma$-GT $\geq 75 \mathrm{U} / \mathrm{L}$ and $<75 \mathrm{U} / \mathrm{L}$ in patients with alcohol cause and patients without alcohol cause.

study of the Neutrophil-Lymphocyte ratio relationship with HCC prognosis revealed the connection between $\gamma$-GT and HCC [8], supporting the retrospective analysis of the present study. We found that for HCC patients with a potentially shortened survival rates, their baseline $\gamma$-GT level could serve as an independent prognostic factor. Furthermore, compared with the most common serum biochemical variables, including Child-Pugh class, tumor characteristics, and MELD stage, a $\gamma$-GT level $\geq 75 \mathrm{U} / \mathrm{L}$ had a higher prognostic value. By subgroup analyses, we also found that patients with a higher $\gamma$-GT level tended to have greater mortality when classified as BCLC stages B-D and TNM stages II-IV. In other words, $\gamma$-GT levels had a high predictive value for patients at middle- or late-stage progression of HCC. In addition, subgroup analyses examining different levels of serum AFP showed that patients with higher $\gamma$-GT levels had a significantly higher mortality. Our results showed that, especially in the AFP-negative subgroups, $\gamma$-GT was a valuable tool in determining the prognosis of HCC patients, which had important clinical significance. These conclusions were not affected by the causative role of alcohol in HCC diagnosis.

It has been reported that the expression of $\gamma$-GT varies among normal tissues. In the capillary endothelial cells of the nervous system, renal proximal convoluted tubules and biliary ducts where absorption and secretion takes place, the activity of $\gamma$-GT is increased $[26,27]$. However, given the different distribution and concentration of $\gamma$-GT among normal tissues, the expression of $\gamma$-GT varies widely across different human carcinomas [28]. Increased expression of $\gamma$-GT has been observed in liver, colon, ovarian cancer, leukemias, astrocytic glioma, and melanoma [29-34].

The underlying mechanisms for the relationship between $\gamma$-GT and tumors, including HCC, remain elusive. Recently, several studies have reported that when $\gamma$-GT is overexpressed, its pro-oxidant effect disturbs the oxidant/antioxidant balance, which plays a role in the continued oxidative stress reaction in the tumor; this in turn is involved in the regulating of tumor progression [14,35]. Additionally, components such as serum inflammatory markers, which are related in the processes of inflammation, have been reported to be closely related to HCC prognosis [36-38]. It has been internationally recognized that $\gamma$-GT level is useful in the evaluation of active chronic hepatitis [39]. Furthermore, $\gamma$-GT levels have been associated with fibrosis stage and cirrhosis at baseline and of helping to predict fibrosis progression [28]. Therefore, as a reflection of the inflamed liver microenvironment in patients with hepatitis [25], $\gamma$-GT may be a promising predictor for prognosis of HCC patients. 
By a large sample statistical analysis, this study showed that, except in cases of portal vein invasion, $\gamma$-GT is of superior value in evaluating the prognosis of HCC patients compared to tumor number, tumor size, lymph node metastasis, levels of ANC, ALC and AFP, and Child-Pugh class. Additionally, $75 \mathrm{U} / \mathrm{L}$ was determined to be the optimal $\gamma$-GT cut-off value, which was different from what has been previously reported [13, 23-25]. Recently, Fu et al show $128 \mathrm{U} / \mathrm{L}$ of $\gamma$-GT is the optimal cut-off value, with a sensitivity and specificity of $60.0 \%$ and $72.9 \%$, respectively [40]. In this study, we showed that $75 \mathrm{U} / \mathrm{L}$ of $\gamma$-GT exerted the sensitivity of $64.9 \%$ and the specificity of $77.0 \%$. It was obvious that $75 \mathrm{U} / \mathrm{L}$ of $\gamma$-GT from our data have a higher sensitivity and specificity. This also raised another possibility that the number of our samples $(n=858)$ is greater than that of the study from Fu et al $(\mathrm{n}=130)$.

In conclusion, this study was the first to find that serum $\gamma$-GT baseline levels at diagnosis aid in the prognosis of HCC patients, which was important for long-term integrated treatment modalities. A $\gamma$-GT level of $\geq 75 \mathrm{U} / \mathrm{L}$ could be used as an important serum biochemical marker for evaluating prognosis of HCC, including in those patients negative for serum AFP, a significant finding for clinicians. Larger samples of prospective randomized multi-center studies were warranted in the future to confirm these results.

Acknowledgements: This study was supported by the National Natural Science Foundation of China (grant nos. 81273743 and 81473641), the 215 Program from Beijing Municipal Health Bureau (2013-2-11) and the Collaborative Innovation Center of Infectious diseases (PXM 2015-014226-000058).

\section{References}

[1] TORRE LA, BRAY F, SIEGEL RL, FERLAY J, LORTETTIEULENT J et al. Global cancer statistics, 2012. CA Cancer J Clin 2015; 65: 87-108. https://doi.org/10.3322/caac.21262

[2] JEMAL A, BRAY F, CENTER MM, FERLAY J, WARD E et al. Global cancer statistics. CA Cancer J Clin 2011; 61: 69-90. https://doi.org/10.3322/caac.20107

[3] TOSHIKUNI N, MATSUE Y, MINATO T, HAYASHI N, TSUTSUMI M. Association between transforming growth factor-beta1 -509 C>T variants and hepatocellular carcinoma susceptibility: a meta-analysis. Neoplasma 2016; 63: 961-966. https://doi.org/10.4149/neo 2016615

[4] TSOCHATZIS EA, MEYER T, BURROUGHS AK. Hepatocellular carcinoma. N Engl J Med 2012; 366: 92-92. https://doi. org/10.1056/NEJMc1112501

[5] KIM WR, GORES GJ, BENSON JT, THERNEAU TM, MELTON LR. Mortality and hospital utilization for hepatocellular carcinoma in the United States. Gastroenterology 2005; 129: 486-93. https://doi.org/10.1016/j. gastro.2005.05.001

[6] LENCIONI R. Loco-regional treatment of hepatocellular carcinoma. Hepatology 2010; 52: 762-773. https://doi. org/10.1002/hep. 23725
[7] CAMMA C, CABIBBO G. Prognostic scores for hepatocellular carcinoma: none is the winner. Liver Int 2009; 29: 478-480. https://doi.org/10.1111/j.1478-3231.2009.01994.x

[8] EDGE SB, COMPTON CC. The American Joint Committee on Cancer: the 7th edition of the AJCC cancer staging manual and the future of TNM. Ann Surg Oncol 2010; 17: 1471-1474. https://doi.org/10.1245/s10434-010-0985-4

[9] ZHANG JF, SHU ZJ, XIE CY, LI Q, JIN XH et al. Prognosis of unresectable hepatocellular carcinoma: comparison of seven staging systems (TNM, Okuda, BCLC, CLIP, CUPI, JIS, CIS) in a Chinese cohort. PLoS One 2014; 9: e88182. https://doi. org/10.1371/journal.pone.0088182

[10] XU JB, QI FZ, XU G, CHEN GF, QIN LX et al. Value of alpha-fetoprotein and clinical characteristics in patients with liver neoplasm. Neoplasma 2014; 61: 218-224. https://doi. org/10.4149/neo $2014 \quad 028$

[11] YAO DF, DONG ZZ, YAO M. Specific molecular markers in hepatocellular carcinoma. Hepatobiliary Pancreat Dis Int 2007; 6: 241-247.

[12] IKEDA Y, TANIGUCHI N. Gene expression of gamma-glutamyltranspeptidase. Methods Enzymol 2005; 401: 408-425. https://doi.org/10.1016/S0076-6879(05)01025-6

[13] ZHANG JB, CHEN Y, ZHANG B, XIE X, ZHANG L et al. Prognostic significance of serum gamma-glutamyl transferase in patients with intermediate hepatocellular carcinoma treated with transcatheter arterial chemoembolization. Eur J Gastroenterol Hepatol 2011; 23: 787-93. https://doi.org/10.1097/ MEG.0b013e32834902dd

[14] CORTI A, FRANZINI M, PAOLICCHI A, POMPELLA A. Gamma-glutamyltransferase of cancer cells at the crossroads of tumor progression, drug resistance and drug targeting. Anticancer Res 2010; 30: 1169-1181.

[15] SILVA IS, FERRAZ ML, PEREZ RM, LANZONI VP, FIGUEIREDO VM et al. Role of gamma-glutamyl transferase activity in patients with chronic hepatitis $\mathrm{C}$ virus infection. J Gastroenterol Hepatol 2004; 19: 314-318. https://doi. org/10.1111/j.1440-1746.2003.03256.x

[16] CIVAN JM. Management of Small Hepatocellular Carcinoma. Radiology 2016; 279: 651-652. https://doi.org/10.1148/ra$\underline{\text { diol.2016152120 }}$

[17] KOUSIK V, PROMILA P, VERMA R, GUPTA A. Role of yttrium-90 in the management of unresectable hepatocellular carcinoma and hepatic metastases. Indian J Gastroenterol 2016; 35: 179-185. https://doi.org/10.1007/s12664-016-0657-9

[18] GAO J, ZOU Z, GAO J, ZHANG H, LIN Z et al. Increased expression of HMGB3: a novel independent prognostic marker of worse outcome in patients with esophageal squamous cell carcinoma. Int J Clin Exp Pathol 2015; 8: 345-352.

[19] ZOU ZZ, NIE PP, LI YW, HOU BX, RUI-LI et al. Synergistic induction of apoptosis by salinomycin and gefitinib through lysosomal and mitochondrial dependent pathway overcomes gefitinib resistance in colorectal cancer. Oncotarget 2015. doi: 10.18632/oncotarget.5628 https://doi.org/10.18632/oncotarget. 5628

[20] NIE P, HU W, ZHANG T, YANG Y, HOU B et al. Synergistic Induction of Erlotinib-Mediated Apoptosis by Resveratrol in Human Non-Small-Cell Lung Cancer Cells by Down-Regulat- 
ing Survivin and Up-Regulating PUMA. Cell Physiol Biochem 2015; 35: 2255-2271. https://doi.org/10.1159/000374030

[21] LUO X, YAO J, NIE P, YANG Z, FENG H et al. FOXM1 promotes invasion and migration of colorectal cancer cells partially dependent on HSPA5 transactivation. Oncotarget 2016; 7: 26480-26495. https://doi.org/10.18632/oncotarget.8419

[22] ZOU Z, YUAN Z, ZHANG Q, LONG Z, CHEN J et al. Aurora kinase A inhibition-induced autophagy triggers drug resistance in breast cancer cells. Autophagy 2012; 8: 1798-1810. https://doi.org/10.4161/auto.22110

[23] GUIU B, DESCHAMPS F, BOULIN M, BOIGE V, MALKA $\mathrm{D}$ et al. Serum gamma-glutamyl-transferase independently predicts outcome after transarterial chemoembolization of hepatocellular carcinoma: external validation. Cardiovasc Intervent Radiol 2012; 35: 1102-1108. https://doi.org/10.1007/ s00270-011-0293-9

[24] JU MJ, QIU SJ, FAN J, ZHOU J, GAO Q et al. Preoperative serum gamma-glutamyl transferase to alanine aminotransferase ratio is a convenient prognostic marker for Child-Pugh A hepatocellular carcinoma after operation. J Gastroenterol 2009; 44: 635-642. https://doi.org/10.1007/s00535-009-0050-X

[25] MA H, ZHANG L, TANG B, WANG Y, CHEN R et al. gammaGlutamyltranspeptidase is a prognostic marker of survival and recurrence in radiofrequency-ablation treatment of hepatocellular carcinoma. Ann Surg Oncol 2014; 21: 3084-3089. https:// doi.org/10.1245/s10434-014-3724-4

[26] HANIGAN MH, FRIERSON HJ. Immunohistochemical detection of gamma-glutamyl transpeptidase in normal human tissue. J Histochem Cytochem 1996; 44: 1101-1108. https:// doi.org/10.1177/44.10.8813074

[27] PETTA S, MACALUSO FS, BARCELLONA MR, CAMMA C, CABIBI D et al. Serum gamma-glutamyl transferase levels, insulin resistance and liver fibrosis in patients with chronic liver diseases. PLoS One 2012; 7: e51165. https://doi. org/10.1371/journal.pone.0051165

[28] EVERHART JE, WRIGHT EC. Association of gamma-glutamyl transferase (GGT) activity with treatment and clinical outcomes in chronic hepatitis C (HCV). Hepatology 2013; 57: 1725-1733. https://doi.org/10.1002/hep.26203

[29] RZYMOWSKA J. Activities of enzyme transducing extracellular signals-gamma glutamyltransferase and enzymes metabolizing glutathione in acute lymphoblastic and myeloid human leukemias. Neoplasma 1995; 42: 53-56.

[30] MOGHADAMRAD S, MONTANI M, WEIMANN R, DE GOTTARDI A. Cholestasis in a patient with gallstones and a normal gamma-glutamyl transferase. Hepatology 2013; 57: 2539-2541. https://doi.org/10.1002/hep.26344

[31] MURATA J, RICCIARDI-CASTAGNOLI P, DESSOUS LMP, MARTIN F, JUILLERAT-JEANNERET L. Microglial cells induce cytotoxic effects toward colon carcinoma cells: measurement of tumor cytotoxicity with a gamma-glutamyl transpeptidase assay. Int J Cancer 1997; 70: 169-174. https:// doi.org/10.1002/(SICI)1097-0215(19970117)70:2<169::AIDIJC6>3.0.CO;2-V

[32] HANIGAN MH, FRIERSON HJ, BROWN JE, LOVELL MA, TAYLOR PT. Human ovarian tumors express gammaglutamyl transpeptidase. Cancer Res 1994; 54: 286-290.

[33] TAGER M, ITTENSON A, FRANKE A, FREY A, GASSEN HG et al. gamma-Glutamyl transpeptidase-cellular expression in populations of normal human mononuclear cells and patients suffering from leukemias. Ann Hematol 1995; 70: 237-242. https://doi.org/10.1007/BF01784042

[34] AL-JAMEIL N, KHAN FA, ARJUMAND S, KHAN MF, TABASSUM H. Associated liver enzymes with hyperlipidemic profile in type 2 diabetes patients. Int J Clin Exp Pathol 2014; 7: 4345-4349.

[35] POMPELlA A, DE TATA V, PAOLICCHI A, ZUNINO F. Expression of gamma-glutamyltransferase in cancer cells and its significance in drug resistance. Biochem Pharmacol 2006; 71: 231-238. https://doi.org/10.1016/j.bcp.2005.10.005

[36] TENG Y, FAN YC, MU NN, ZHAO J, SUN FK et al. Serum SOX11 promoter methylation is a novel biomarker for the diagnosis of Hepatitis B virus-related hepatocellular carcinoma. Neoplasma 2016; 63: 419-426. https://doi.org/10.4149/311 151029N552

[37] GAO Y, LI Z, GUO X, LIU Y, ZHANG K. DLX4 as a prognostic marker for hepatocellular carcinoma. Neoplasma 2014; 61: 318-323. https://doi.org/10.4149/neo 2014 041

[38] HANAHAN D, WEINBERG RA. Hallmarks of cancer: the next generation. Cell 2011; 144: 646-674. https://doi.org/10.1016/j. cell.2011.02.013

[39] SILVA IS, FERRAZ ML, PEREZ RM, LANZONI VP, FIGUEIREDO VM et al. Role of gamma-glutamyl transferase activity in patients with chronic hepatitis $\mathrm{C}$ virus infection. J Gastroenterol Hepatol 2004; 19: 314-318. https://doi. org/10.1111/j.1440-1746.2003.03256.x

[40] FU SJ, ZHAO Q, JI F, CHEN MG, WU LW et al. Elevated Preoperative Serum Gamma-glutamyltranspeptidase Predicts Poor Prognosis for Hepatocellular Carcinoma after Liver Transplantation. Sci Rep 2016; 6: 28835 https://doi. org/10.1038/srep28835 